\section{Model Simulation of Cucumber Yield and Microclimate Analysis in a Semi-closed Greenhouse in China}

\author{
Xiaotao Ding ${ }^{1}$ \\ Shanghai Dushi Green Engineering Co., Ltd., Horticultural Research \\ Institute, Shanghai Academy of Agricultural Sciences, Shanghai 201106, \\ China; and School of Agriculture and Biology, Shanghai Jiao Tong \\ University, Shanghai 202400, China
}

Yuping Jiang ${ }^{1}$

Shanghai Dushi Green Engineering Co., Ltd., Horticultural Research Institute, Shanghai Academy of Agricultural Sciences, Shanghai 201106, China

\section{Dafeng Hui}

Department of Biological Sciences, Tennessee State University, Nashville, TN 37209

\section{Lizhong He}

Shanghai Dushi Green Engineering Co., Ltd., Horticultural Research Institute, Shanghai Academy of Agricultural Sciences, Shanghai 201106, China

\section{Danfeng Huang \\ School of Agriculture and Biology, Shanghai Jiao Tong University, Shanghai 202400, China}

\section{Jizhu $\mathbf{Y u}^{2}$ and Qiang Zhou ${ }^{2}$ \\ Shanghai Dushi Green Engineering Co., Ltd., Horticultural Research Institute, Shanghai Academy of Agricultural Sciences, Shanghai 201106, China}

Additional index words. semi-closed greenhouse, cucumber, microclimate parameters, regression analysis, statistical modeling

Abstract. Adequate greenhouse environmental management is very important for improving resource use efficiency and increasing vegetable yield. The objective of this study was to explore suitable climate and cultivation management for cucumber to achieve high yield and build optimal yield models in semi-closed greenhouses. A fruit cucumber cultivar Deltastar was grown over 4 years in greenhouse and weekly data of yields (mean, highest and lowest) and environmental variables, including total radiation, air temperature, relative humidity, and carbon dioxide $\left(\mathrm{CO}_{2}\right)$ concentration were collected. Regression analyses were applied to develop the relationships and build best regression models of yields with environmental variables using the first 2 years of data. Data collected in years 3 and 4 were used for model validation. Results showed that total radiation, nutrient, temperature, $\mathrm{CO}_{2}$ concentration, and average nighttime relative humidity had significant correlations with cucumber yields. The best regression models fit the mean, lowest, and highest yields very well with $R^{2}$ values of $0.67,0.66$, and 0.64 , respectively. Total radiation and air temperature had the most significant contributions to the variations of the yields. Our results of this study provide useful information for improving greenhouse climate management and yield forecast in semi-closed greenhouses.

Greenhouse cultivation of vegetables has been widely used to extend the crop-growing season and protect crops from unfavorable environmental conditions in China, especially during winter time in central and northern China. Both quality and production of vegetable in the greenhouses are often improved compared with field cultivation (Dorais et al., 2001). Over the past decade, semi-closed greenhouses (i.e., greenhouses with reduced window opening) have been developed in the Netherlands to conserve energy and provide better growth conditions (Qian et al., 2011). Compared with conventional greenhouses, climate conditions in these greenhouses differ considerably. In the semi-closed greenhouse, the excess solar energy in summer is collected and stored, and reused to heat the greenhouse in winter (Opdam et al., 2005). The greenhouse air can be heated, cooled, and dehumidified by air circulation units and returned to the greenhouse through heating or cooling ducts. It has much larger dimensions and more powerful climate control equipment, which can supply very specific growing conditions for the study of different crops (Alsadon et al., 2016; Qian et al., 2015). The aim of the semi-closed greenhouse is to recover excess heat to satisfy the heating requirements while keeping the environmental conditions as favorable as possible for plant growth (Boulard et al., 2017).

Cucumber (Cucumis Sativus L.) is a popular vegetable in China and considered as a favorite greenhouse crop. Cucumber also shows a cyclic growth pattern in which periods of high fruit setting and slow fruit growth alternate with periods of low fruit setting and rapid fruit growth (Marcelis, 1992). So far, most studies of cucumber in the greenhouse have been done on greenhouse management, cucumber growth, and yield models. For example, to increase the efficiency of the crop production process, Boaventura and de Moura (2003) studied an optimal management practice of greenhouse environments related to capital investments, crop selection, and labor. Xu et al. (2010) simulated cucumber growth based on temperature and radiation at different latitudes and different planting densities. In autumn, winter, and spring, $\mathrm{CO}_{2}$ concentrations may drop to very low levels $\left(\approx 200 \mu \mathrm{mol} \cdot \mathrm{mol}^{-1}\right)$ due to $\mathrm{CO}_{2}$ uptake by the plants and limited ventilation. Kläring et al. (2007) studied that model-based control of $\mathrm{CO}_{2}$ concentration in greenhouses can effectively increase cucumber yield due to the enhanced leaf photosynthesis under higher $\mathrm{CO}_{2}$ concentration enrichment in the greenhouses. Similar results were reported by Nederhoff and Vegter (1994). Dai et al. (2011) quantified the effects of nitrogen on fruit growth and yield of cucumber in greenhouses, and developed a model to assess cucumber production systems and methodologies for improving greenhouse climate management and cucumber yield, and reducing adverse impact on plant growth. But these models usually aim at predicting potential greenhouse crop growth and yield under optimal growth conditions; hence, sometimes cannot be directly applied for crops grown under actual greenhouse conditions.

To the best of our knowledge, cucumber cultivation in the semi-closed greenhouse has been practiced in China for only a few years. A comprehensive climate values analysis and modeling study that related solar radiation, temperature, humidity, $\mathrm{CO}_{2}$, irrigation, and other climatic variables to cucumber yields in the semi-closed greenhouses is needed. In this experiment, we grew cucumber plants in semi-closed greenhouses and collected climatic values and cucumber yields for 4 years ( 2 years of data for model development and 2 years of data for validation). The main objective of the experiment was to analyze the changes of climate values and develop a model that can predict the yield of cucumber 
by optimizing environmental variables for greenhouse cucumber production.

\section{Materials and Methods}

Greenhouse management. A semi-closed Venlo-type greenhouse on a farm located on the Shanghai Chongming Island (lat. $31^{\circ} 34^{\prime} \mathrm{N}$, long. $121^{\circ} 41^{\prime} \mathrm{E}$ ) was used in this study. The cultivation area of the greenhouse was composed of 10 greenhouse compartments $(24 \times 35 \mathrm{~m})$, each with three spans, with 8-m span size in the north-south direction, and seven sections with each one $5-\mathrm{m}$ section size in the east-west direction. Two greenhouse compartments were used for cucumber cultivation with the same climate controls and management. The heights of gutter and ridge were $7.3 \mathrm{~m}$ and $8.25 \mathrm{~m}$, respectively. There were three ridge ventilators on each of the north and south sides of the 4-m roof. Each window was $2.5 \mathrm{~m}$ (length) $\times$ $1.2 \mathrm{~m}$ (width), with a fully open height of $0.9 \mathrm{~m}$. The greenhouse has three curtains: outside shading curtain ( $9.35 \mathrm{~m}$ high, $40 \%$ shading in full closed condition), inside shading curtain $(7.15 \mathrm{~m}$ high, $50 \%$ shading in full closed condition), and inside energysaving curtain $(6.65 \mathrm{~m}$ high, $20 \%$ shading in full closed condition). Each greenhouse compartment has seven air treatment units (ATUs; each has $33 \mathrm{~kW}$ cooling capacity and $27.4 \mathrm{~kW}$ heating capacity, with $4500 \mathrm{~m}^{3} / \mathrm{h}$ air flow), with $\approx 30$-m plastic tubes (diameter $50 \mathrm{~cm}$ ) that can transport energy to the greenhouse for heating, cooling, dehumidifying, and air circulation. There are two air circulation fans ( $260 \mathrm{~W}$ each) fixed in the front and at the back of the greenhouse $\approx 6 \mathrm{~m}$ high. The growing gutters were placed $0.8 \mathrm{~m}$ above the ground. The ground surface of the greenhouse was covered with plastic film, with the exception of a $2.5-\mathrm{m}$ wide, concrete path situated along the west wall. The tube rail heating pipes (diameter $51 \mathrm{~mm}$ ) were supported $\approx 15 \mathrm{~cm}$ above the ground, which can be used for greenhouse heating and trolley moving.

The energy systems of the semi-closed greenhouse include groundwater sources

Received for publication 2 Nov. 2018. Accepted for publication 14 Dec. 2018.

This work was supported by the Agricultural Basic Research of the Shanghai Agriculture Commission (7-2-1, 2014), Natural Science Foundation of Shanghai (18ZR1433200), and Shanghai Agriculture Committee Promotion Project $(2-5-8,2016)$. The funders had no role in study design, data collection and analysis, decision to publish, or preparation of the manuscript.

Author contributions: Conceived and designed the experiments: Q.Z., J.Y., X.D. Performed the experiments: X.D., Y.J., L.H. Analyzed the data: Y.J., X.D., D.Huang. Contributed reagents/materials/ analysis tools: X.D., Q.Z., D.Hui. Wrote the paper: X.D., J.Y. The authors declare no competing interests.

${ }^{1}$ Contributed equally to this work.

${ }^{2}$ Corresponding authors. E-mail: 13636569665@ 163.com or zhou.qiang@dushigreen.com. (hot- and cold-water wells), groundwater energy exchange system (high-efficiency plate energy exchanger), heat pump, the end system (greenhouse heating ducts and ATU), and energy storage system (heat storage tank and cold storage tank). The operation manners of energy systems and climate controls can be referenced in De Gelder et al. (2012), Gieling et al. (2011), and Kaukoranta et al. (2014), which mainly depend on energysaving strategies and commercial crop management practices in China.

Air temperature, relative humidity, and $\mathrm{CO}_{2}$ concentration in the greenhouse were monitored and controlled automatically (Gieling et al., 2011). Measurements were recorded automatically at 5-min intervals using one climate sensor (Priva, De Lier, the Netherlands) per greenhouse, placed at the top of the canopy, and moved up and down based on plant heights $(\approx 20 \mathrm{~cm}$ higher than plant head). The other climate variables (such as radiation) and irrigation information [such as nutrient solution quantity and frequency, electrical conductivity (EC), and $\mathrm{pH}$ ] were also recorded automatically by the corresponding Priva sensors. All the climate and irrigation information were recorded by a computer. There was no supplemental $\mathrm{CO}_{2}$ enrichment in all experimental greenhouses. $\mathrm{CO}_{2}$ enrichment was carried out by natural ventilation and ATU air circulation during the cucumber growth. In summer, when cooling energy was not enough to reduce temperature for adequate cucumber growth (very high outside temperature, almost reaching to $40{ }^{\circ} \mathrm{C}$ in some extreme days), we managed the greenhouse temperature mainly by ATU air circulation and outside shading curtains (Duarte-Galvan et al., 2012).

Crop management. Seeds of cucumber (Cucumis Sativus L. cv. Deltastar) were sowed directly in water-soaked rockwool blocks $(10 \times 10 \times 6.5 \mathrm{~cm})$ and then covered with vermiculite substrate. In each cultivation practice, cucumber seedlings with the same size were planted on rockwool slabs $(100 \times 20 \times 7.5 \mathrm{~cm})$ in the greenhouse and irrigated by drip fertigation. Plants were pruned to a single stem and one flower was kept at each node (one flower was kept at two nodes at the end of harvest) from the sixth node onward. Stem density was $2.8 \mathrm{stems} / \mathrm{m}^{2}$ and used a high-wire growing system. Each greenhouse compartment was separated by 16 cultivation lines and maintained at least eight lines for Deltastar in each cucumber cultivation practice. Normally, we harvested fruits every day, pruned three leaves 4 to $5 \mathrm{~d}$ and maintained 15 to 18 leaves for the plant photosynthesis, turned the plant's head once every $3 \mathrm{~d}$ and lowered plants once every 4 to $5 \mathrm{~d}$. The irrigation nutrient solution strategy was 2 to $3 \mathrm{~mL} \cdot \mathrm{m}^{-2}$ water per $\mathrm{J} \cdot \mathrm{cm}^{-2}$ radiation accumulation for adult plants. EC of 2.0 to $2.5 \mathrm{dS} \cdot \mathrm{m}^{-1}$ and $\mathrm{pH}$ of 5.5 were maintained before cucumber harvest. Once harvesting started, EC of 2.5 to $3.0 \mathrm{dS} \cdot \mathrm{m}^{-1}$ and $\mathrm{pH}$ of 5.5 were maintained. It is important to adjust the irrigation strategies to make sure the drain of nutrient solution reaches $20 \%$ to $30 \%$ of the applied every day.

Biological control was mainly used to protect cucumber from pests and diseases. The tea mites (Polyphagotarsonemus latus Banks) and white flies were the main pests in the greenhouse. We used a predator mite (Neoseiulus cucumeris Oudemans) to control pests and it worked reasonably well. When biological control failed, we used a biological soap (a ratio of $50 \approx 100: 1$ water to soap; Rui Xue Global, Beijing, China) to spray the plants and made all the leaves well wet. Meanwhile, the operating of ATU made a slight positive pressure in the semi-closed greenhouse, and a small wind would blow out when the greenhouse door was opened, which could block airborne pathogens and pests. The relative humidity was set to be below 95\% and the greenhouse was air circulated well at night, so there were mostly no fungal diseases for the plants, especially no occurrence of downy mildew. Deltastar is also resistant to disease, especially powdery mildew.

Cucumber growth, yield, and measurements. There were 14 cultivation and harvest periods of cucumber in 2014-17: 1) week 1 to 8, 2014, 8 weeks of harvest time; 2) week 15 to 20 , 2014, 6 weeks; 3) week 25 to $31,2014,7$ weeks; 4) week 41 to 52, 2014 and week 1 to 9, 2015, 21 weeks; 5) week 14 to $29,2015,16$ weeks; 6) week 31 to $36,2015,6$ weeks; and 7) week 41 to $52,2015,12$ weeks; 8) week 1 to 12, 2016, 12 weeks; 9) week 13 to 25,2016 , 13 weeks; 10) week 30 to $35,2016,6$ weeks; 11) week 40 to 52,2016 and week 1 to 7,2017 , 20 weeks; 12) week 14 to $26,2017,13$ weeks; 13) week 30 to $35,2017,6$ weeks; and 14) week 41 to $52,2017,12$ weeks. We used cucumber yield data and environmental factors of 2014-15 to construct the models, and validated the models with yield data and environmental factors of 2016-17. For each cultivation and harvest period, we removed the first and last week yield data to avoid nonfull week and unreliable data used for analysis. Fruits were mostly harvested daily, and all fruits harvested in the week were added together as the yield of week. Yield of each cucumber line harvested in a week was used to calculate the mean yield, the lowest yield, and the highest yield of the week. When the cucumber yield was clearly decreased or the situation was not suitable for harvest (such as harvest time 2; the tea mites emerged suddenly and the first time, they were spreading quickly and the plants suffered serious stress, which resulted in plant growth stagnation and yield decreased clearly), we would stop the cucumber growth and harvest.

Measurements of environmental factors were downloaded from the computer and used to calculate mean daily values, nighttime values, or means of 24-hour measurements for each week. Ten independent environmental factors and three yield variables were calculated: T_day $=$ average air temperature of weekly daytime; T_night = average air temperature of weekly nighttime; 
$\mathrm{T} \_$ave $=$average air temperature of weekly 24-hour; RH_day = average relative humidity of weekly daytime; RH_night = average relative humidity of weekly nighttime; RH_ave = average relative humidity of weekly 24-hour; $\mathrm{CO}_{2}$ day = average $\mathrm{CO}_{2}$ concentration of weekly daytime; $\mathrm{CO}_{2} \_$night $=$ average $\mathrm{CO}_{2}$ concentration of weekly nighttime; $\mathrm{CO}_{2}$ ave $=$ average $\mathrm{CO}_{2}$ concentration of weekly 24-hour; R_sum = total weekly solar radiation; Yield_ave = average cucumber yield of weekly measured; Yield_L = lowest cucumber yield of weekly measured; and Yield_H $=$ highest cucumber yield of weekly measured.

Statistical modeling. To estimate the cucumber yields, we developed the best regression models of yields with environmental factors of 2014-15. We first tested the relationships between yields and environmental factors to see if linear regression models were adequate. We found that all environmental variables measured had linear or no relationships with yield except temperature, which showed a quadratic relationship with yield. Thus, we included temperature*temperature as a variable in multiple regression analysis. Cucumber yield models were constructed using multiple linear regression model with backward model selection method. Nonsignificant variables were eliminated from the models until all variables in the models were significant. The model validation was conducted using data collected from 2016-17. All data analyses were performed using Statistical Analysis System (SAS version 9.3; SAS Institute Inc., Cary, NC). Figures were plotted using Origin 7.0 software (Origin Laboratory, Northampton, MA).

\section{Results}

Changes of environmental factors and yields of cucumber in the greenhouse over 2 years. Several environmental factors, such as temperature, relative humidity, and radiation displayed obvious seasonal variations (Fig. 1). There were clear parabola patterns of temperature changes from the first week to the last week in 2014 and 2015. From greenhouse energy system control, we made sure the lowest average air temperature of weekly nighttime (T_night) was above $15^{\circ} \mathrm{C}$ in winter, and the highest average air temperature of weekly daytime (T_day) was not higher than $32{ }^{\circ} \mathrm{C}$ in summer. The relative humidity changes were not much regular from the first 2 years of data. Normally, average relative humidity of weekly daytime (RH_day) was lower than average relative humidity of weekly 24-hour (RH_ave), and $\mathrm{RH}$ _ave was lower than the average relative humidity of weekly nighttime (RH_night), except when it was raining or during waterspraying time. The greenhouse $\mathrm{CO}_{2}$ concentration (including $\mathrm{CO}_{2}$ day, average $\mathrm{CO}_{2}$ concentration of weekly daytime; $\mathrm{CO}_{2}$ night, average $\mathrm{CO}_{2}$ concentration of weekly nighttime; $\mathrm{CO}_{2}$ ave, average $\mathrm{CO}_{2}$ concentration of weekly 24-hour) was higher in winter (2014), and gradually dropped in spring, and increased to some extent in summer (2015, Fig. 1). Total weekly solar radiation (R_sum) showed a similar pattern as temperature, but sometimes R_sum was lower in summer due to the rainy days that occurred more frequently in summer in Shanghai.

The yields (including Yield_ave, average cucumber yield of weekly measured; Yield_L, lowest cucumber yield of weekly measured; and Yield_H, highest cucumber yield of weekly measured) of cucumber also showed seasonal variations (Fig. 2). Yields gradually increased from spring to summer, and dropped from fall to winter. The lowest yields took place in winter, and the highest in spring (Fig. 2).

Correlations between yields and environmental factors. Pearson correlation coefficients between yields and environmental factors were estimated using correlation analysis (Table 1). Yields (Yield_ave, Yield_L, and Yield_H) were significantly correlated with temperatures (T_day, T_night, and T_ave, average air temperature of weekly 24-hour), $\mathrm{RH}$ _night, $\mathrm{CO}_{2}$ concentrations $\left(\mathrm{CO}_{2}\right.$ day, $\mathrm{CO}_{2}$ night, and $\mathrm{CO}_{2}$ ave), and $\mathrm{R} \_$sum, but not with RH_day and RH_ave.

Among environmental factors, the correlation coefficients between temperature (including T_day, T_night, and T_ave) and all other variables were significant (Table 1). Strong correlations were found between temperatures and R_sum. RH_night showed more significant correlations with other environmental factors compared with $\mathrm{RH}$ _day and $\mathrm{RH}$ _ave. $\mathrm{CO}_{2}$ day, $\mathrm{CO}_{2}$ night, and $\mathrm{CO}_{2}$ ave also had significant correlations with other factors, except $\mathrm{CO}_{2}$ day had no significant correlation with $\mathrm{RH}$ _night and RH_ave. All the environmental factors, except RH_ave, showed significant correlations with R_sum.

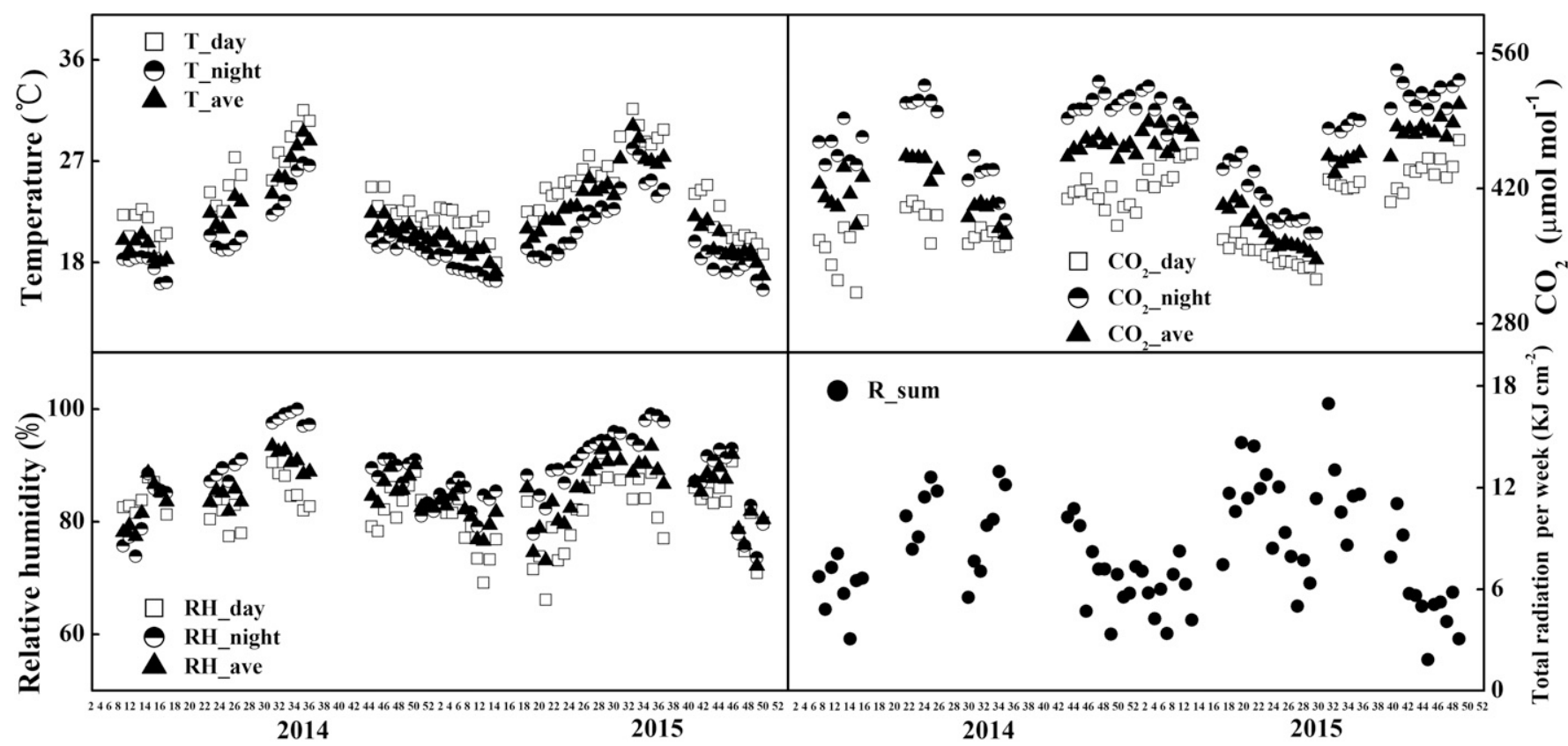

Fig. 1. Weekly measurements of environmental factors over 2 years $(2014-15) . \mathrm{CO}_{2}$ ave $=$ average $\mathrm{CO}_{2}$ concentration of weekly 24 -hour; $\mathrm{CO}_{2}$ day $=$ average $\mathrm{CO}_{2}$ concentration of weekly daytime; $\mathrm{CO}_{2}$ night $=$ average $\mathrm{CO}_{2}$ concentration of weekly nighttime; $\mathrm{RH}$ _ave = average relative humidity of weekly 24 -hour; RH_day = average relative humidity of weekly daytime; $\mathrm{RH} \_n i g h t=$ average relative humidity of weekly nighttime; R_sum = total weekly solar radiation; $\mathrm{T} \_$ave $=$average air temperature of weekly 24 -hour; $\mathrm{T} \_$day $=$average air temperature of weekly daytime; $\mathrm{T} \_$night $=$average air temperature of weekly nighttime. 


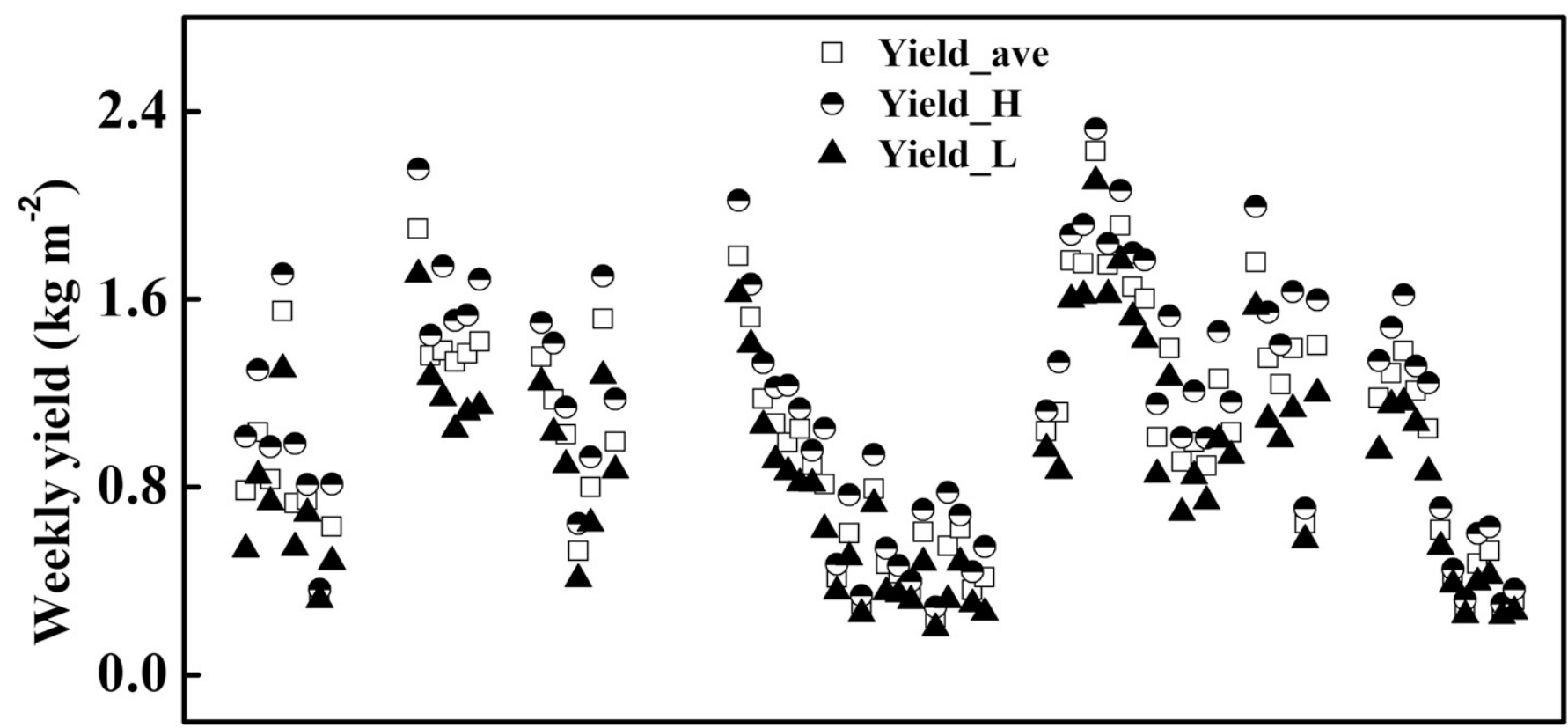

24681214161820222426283032343638404244464850522468121416182022242628303234363840424446485052 2014 2015

Fig. 2. Changes of cucumber yield over 2 years (2014-15). Yield_ave = average cucumber yield of weekly measured; Yield_H = highest cucumber yield of weekly measured; Yield_L = lowest cucumber yield of weekly measured.

Table 1. Correlation of different climate variables and cucumber yield.

\begin{tabular}{|c|c|c|c|c|c|c|c|c|c|c|c|c|}
\hline & T_day & T_night & T_ave & RH_day & RH_night & RH_ave & $\mathrm{CO}_{2 \_ \text {day }}$ & $\mathrm{CO}_{2 \_n i g h t}$ & $\mathrm{CO}_{2 \_ \text {ave }}$ & R_sum & Yield_ave & Yield_H \\
\hline R⿳亠二口犬_day & 0.269 & 0.419 & 0.329 & & & & & & & & & \\
\hline RH_night & 0.753 & 0.762 & 0.772 & 0.532 & & & & & & & & \\
\hline $\mathrm{CO}_{2 \_ \text {day }}$ & -0.346 & -0.288 & -0.344 & -0.243 & -0.155 & -0.160 & & & & & & \\
\hline $\mathrm{CO}_{2}$ night & -0.468 & -0.500 & -0.513 & -0.236 & -0.382 & -0.304 & 0.788 & & & & & \\
\hline $\mathrm{CO}_{2}$ ave & -0.482 & -0.460 & -0.504 & -0.234 & -0.338 & -0.266 & 0.925 & 0.954 & & & & \\
\hline Yield_H & 0.505 & 0.400 & 0.481 & -0.029 & 0.335 & 0.151 & -0.381 & -0.314 & -0.399 & 0.694 & 0.993 & \\
\hline Yield_L & 0.469 & 0.355 & 0.443 & -0.066 & 0.320 & 0.123 & -0.386 & -0.326 & -0.408 & 0.690 & 0.991 & 0.975 \\
\hline
\end{tabular}

Data with bold fonts mean significant difference at $\alpha=0.05$ level.

$\mathrm{CO}_{2}$ ave $=$ average $\mathrm{CO}_{2}$ concentration of weekly 24 -hour; $\mathrm{CO}_{2}$ day $=$ average $\mathrm{CO}_{2}$ concentration of weekly daytime; $\mathrm{CO}_{2}$ night $=$ average $\mathrm{CO}_{2}$ concentration of weekly nighttime; $\mathrm{RH} \_$ave $=$average relative humidity of weekly 24-hour; $\mathrm{RH} \_$day $=$average relative humidity of weekly daytime; $\mathrm{RH}$ night $=$ average relative humidity of weekly nighttime; R_sum = total weekly solar radiation; T_ave = average air temperature of weekly 24-hour; T_day = average air temperature of weekly daytime; T_night = average air temperature of weekly nighttime; Yield_ave = average cucumber yield of weekly measured; Yield_H = highest cucumber yield of weekly measured; Yield_L = lowest cucumber yield of weekly measured.

Bivariate regression analysis of yields and environmental factors. The environmental factors significantly influenced cucumber yields (Yield_ave, average cucumber yield of weekly measured). We further checked whether a nonlinear regression model could better explain the variations of yields. For temperature, we found that quadratic models provided better estimation for yields than linear regression models, with determination coefficient $\left(R^{2}\right)$ of $0.41,0.27$, and 0.40 (all $P<0.0001)$ for T_ave, T_night, and T_day, respectively (Fig. 3). The relationships between yields and $\mathrm{CO}_{2}$ ave, $\mathrm{CO}_{2}$ night, $\mathrm{CO}_{2}$ day, $\mathrm{RH}$ _night, and $\mathrm{R} \_$sum, were fit well with linear regression models, with $R^{2}$ of $0.17(P=0.0002), 0.11(P=0.0042), 0.15$ $(P=0.0005), 0.11(P=0.0035)$, and $0.50(P<$ 0.0001 ), respectively (Fig. 3).
Best regression models of yields with environmental factors using multiple regression analysis. Multiple regression analysis was conducted for cucumber yields with environmental factors. As temperature influenced yield following a quadratic pattern, we also included temperature*temperature as a variable in the models. We used backward model selection method to eliminate all nonsignificant environmental factors, and developed the best regression models for yields (Fig. 4). For Yield_ave, Yield_L, and Yield_H, the best regression models explained $67 \%, 66 \%$, and $64 \%$ of the variations (all $P<0.0001, \mathrm{n}=82$ ). The models fit the measured yields to some extent very well. The $R^{2}$ of model was $0.67,0.62$, and 0.65 (all $P<0.0001$ ) for Yield_ave, Yield_L, and Yield_H, respectively (Fig. 4). Estimate yields matched the seasonal variations (Fig. 4A-C). Actual yields were slightly overestimated, but measured yields of weeks 19 to 31,2016, and weeks 1 to 7, 2017, were clearly lower than simulated data (Fig. 4A-F). Overall, temperature and solar radiation played important roles in cucumber yields. Yield_ave and Yield_L were also positively related to RH_ave.

\section{Discussion}

Growth and yield of cucumber in greenhouses are influenced by many factors, such as solar radiation, temperature, and water irrigation conditions (De Gelder et al., 2012). Light is one of the most important environmental factors, and the energy source for photosynthesis for plant growth 


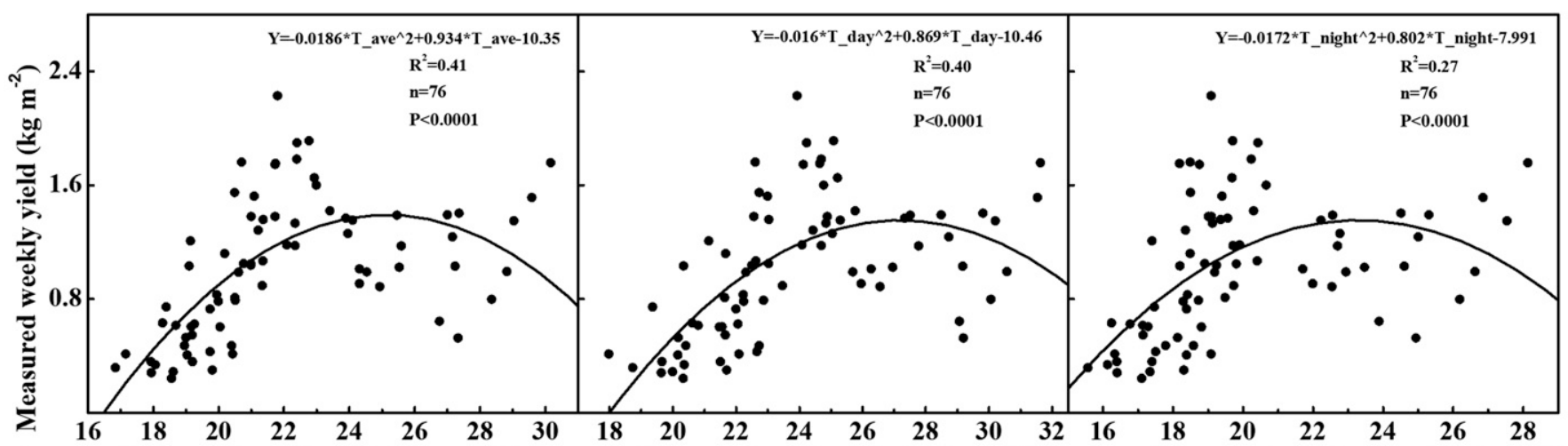

Average air temperature of weekly 24 -hour $\left({ }^{\circ} \mathrm{C}\right)$ Average air temperature of weekly daytime $\left({ }^{\circ} \mathrm{C}\right)$ Average air temperature of weekly nighttime $\left({ }^{\circ} \mathrm{C}\right)$
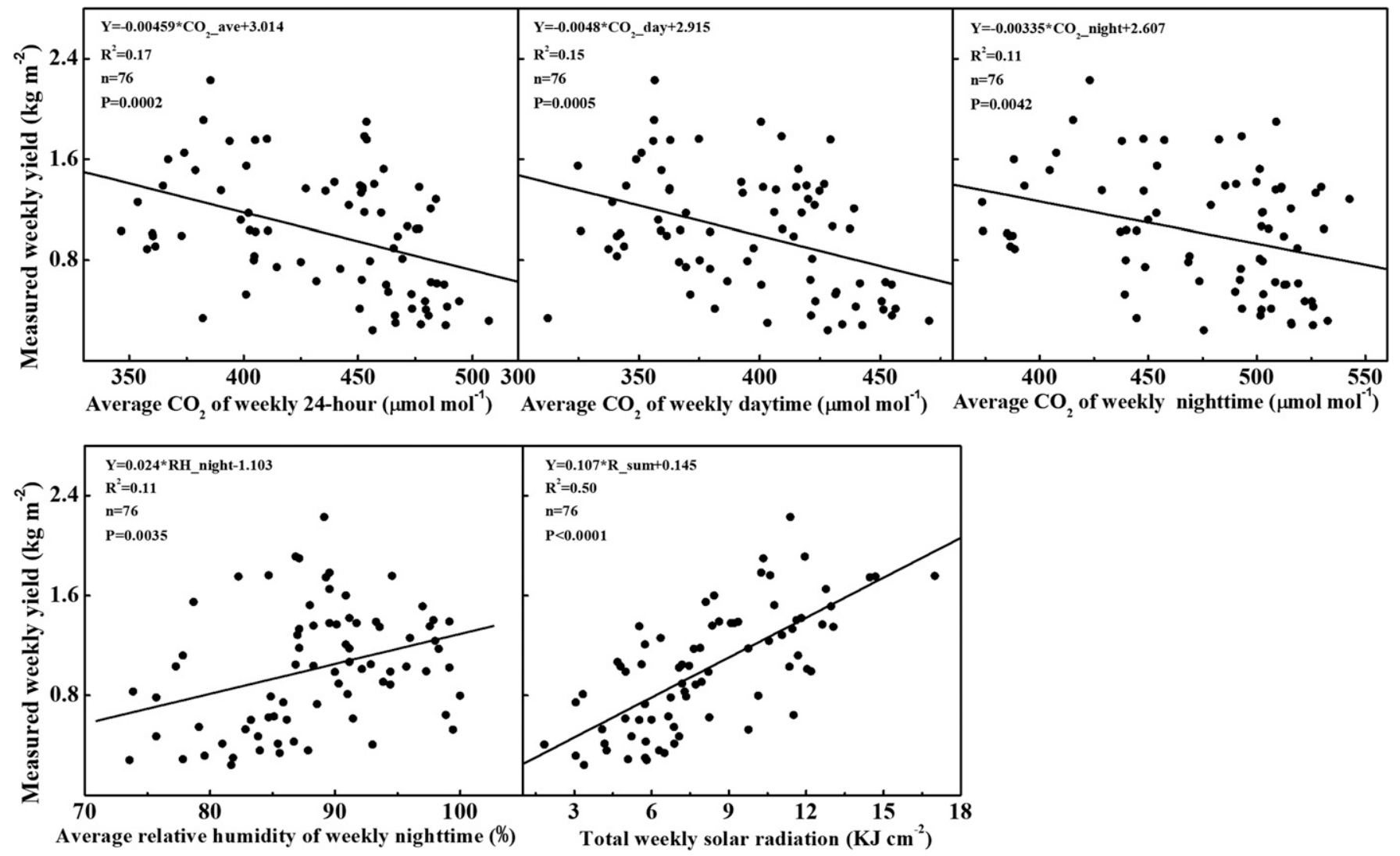

Fig. 3. Regression analysis of yields (Yield_ave, average cucumber yield of weekly measured) and significant environmental factors in $2014-15 . \mathrm{CO}_{2}$ day $=$ average $\mathrm{CO}_{2}$ concentration of weekly daytime; $\mathrm{CO}_{2}$ night $=$ average $\mathrm{CO}_{2}$ concentration of weekly nighttime; $\mathrm{RH}$ _night $=$ average relative humidity of weekly nighttime; R_sum = total weekly solar radiation; T_ave = average air temperature of weekly 24-hour; T_day = average air temperature of weekly daytime; T_night $=$ average air temperature of weekly nighttime.

(Vandenbussche et al., 2003). For most greenhouse vegetable crops, $1 \%$ reduction in solar radiation results in $0.7 \%$ to $1.0 \%$ less growth and production (Marcelis et al., 2006). Ding et al. (2013) found that low light seriously affected cucumber photosynthetic productivity and growth. In this study, we found that yields of cucumber were significantly influenced by R_sum, but also regulated by air temperature (Fig. 1; Table 1). Greenhouse temperature was also related to solar radiation. A clear sunny day can heat the greenhouse and increase the greenhouse temperature quickly (Ding et al., 2016). The more solar radiation received, the more cucumber yield could be achieved, as crop production often shows a linear relation to cumulative solar radiation (Cockshull, 1988; Marcelis et al., 1998). Normally, cucumber can grow well and produce a high yield (reach or exceed $1.5 \mathrm{~kg} \cdot \mathrm{m}^{-2} \cdot$ week $^{-1}$ ) when R_sum reached 10 to $-13 \mathrm{KJ} \cdot \mathrm{cm}^{-2}$ per week (Fig. 3).

Greenhouse temperature is another factor that could affect the metabolic process of photosynthesis, respiration, and transpiration, as well as the organic synthesis and transporting of water and fertilizer (Tian et al., 2014). Our results showed that the greenhouse temperature had significant correlations with RH_night, $\mathrm{RH} \_$ave, and R_sum (Table 1). Cucumber could grow fast and accumulate more organic matter when plants grew in the optimal temperature range
(Li et al., 2014). Our results showed that cucumber would produce the highest yield when T_ave was $\approx 25^{\circ} \mathrm{C}$, T_day $27{ }^{\circ} \mathrm{C}$, and T_night $23{ }^{\circ} \mathrm{C}$ (Fig. 3).

In greenhouses, too high relative humidity could cause fungal diseases, especially for cucumber downy mildew (Lebeda and Cohen, 2011). On the contrary, if the relative humidity was too low, the vapor pressure difference would be too high, which was also not unfavorable for crop growth (Fanourakis et al., 2011). In our experiment, the greenhouse relative humidity was significantly correlated with air temperatures, and $\mathrm{RH}_{-}$ night was correlated with all variables except $\mathrm{CO}_{2}$ day (Table 1). The correlation coefficients between yields and RH_night 

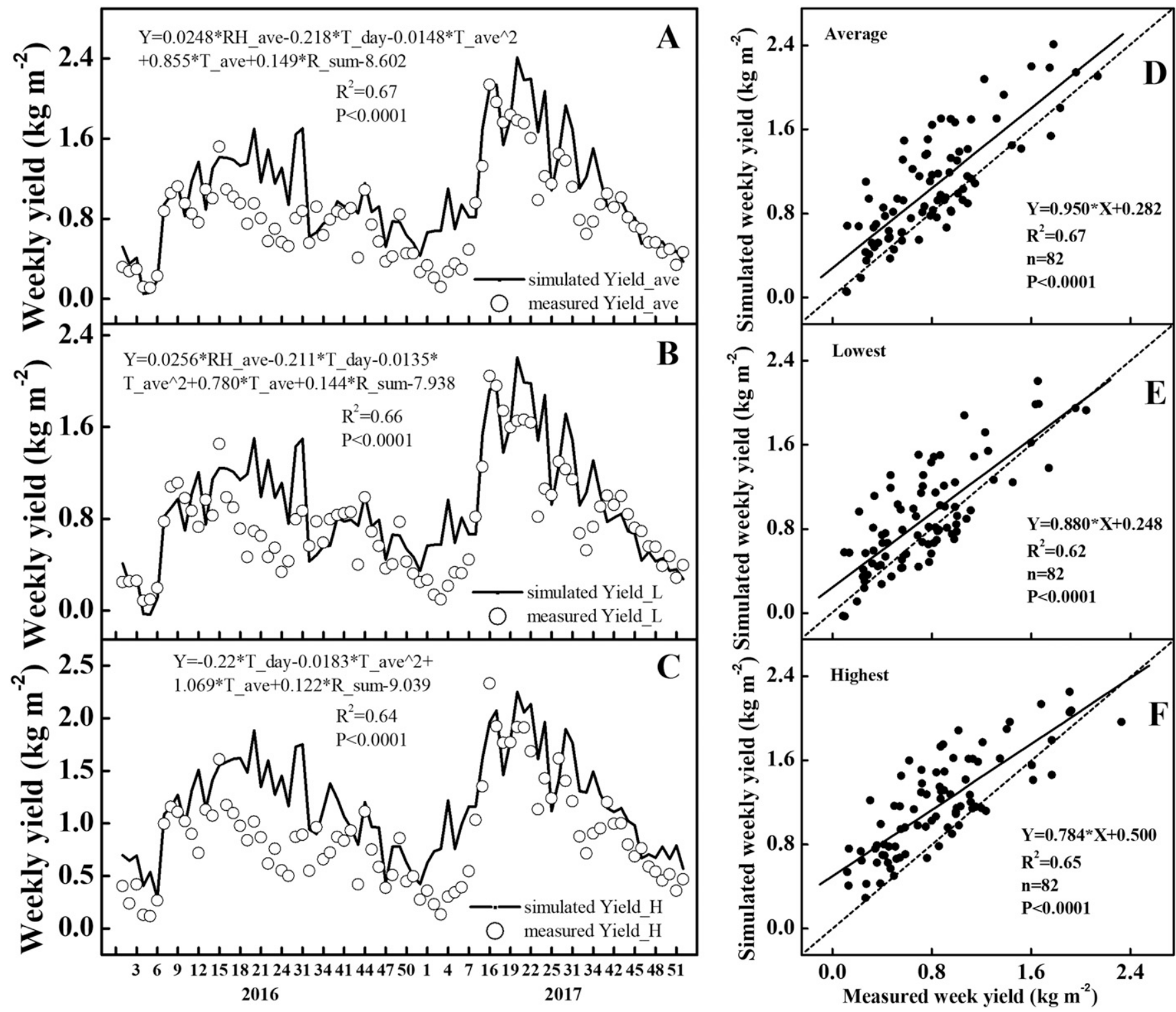

Fig. 4. Best regression models of yields (weekly mean, highest, and lowest) with environmental factors and model validation with measured data (2016-17). Variations of simulated and measured yields are shown over 2 years $(\mathbf{A}-\mathbf{C})$, and simulated and measured yields are compared for model fitting $(\mathbf{D}-\mathbf{F})$. $\mathrm{RH} \_$ave $=$ average relative humidity of weekly 24-hour; $R \_s u m=$ Total weekly solar radiation; T_ave = average air temperature of weekly 24-hour; T_day = average air temperature of weekly daytime; Yield_ave = average cucumber yield of weekly measured; Yield_H = highest cucumber yield of weekly measured; Yield_L = lowest cucumber yield of weekly measured.

were significant. This showed again that cucumber plants like higher relative humidity, but too high relative humidity also reduced crop growth and yield.

$\mathrm{CO}_{2}$ concentration in the greenhouse may influence cucumber growth and yield, as $\mathrm{CO}_{2}$ is needed for plant photosynthesis. The promoting effect of increasing $\mathrm{CO}_{2}$ concentration on leaf photosynthesis is well known and has been described in many studies (Kläring et al., 2007; Liu et al., 2018; Qian et al., 2012; Zhou et al., 2011). But in our greenhouse, $\mathrm{CO}_{2}$ was not enriched or controlled, which only refreshed and supplemented to the greenhouse by the ATU and ridge windows. As a result, $\mathrm{CO}_{2}$ day was low (the lowest level of $\approx 300 \mu \mathrm{mol} \cdot \mathrm{mol}^{-1}$, which was clearly higher than other typical greenhouses with $\approx 200 \mu \mathrm{mol} \cdot \mathrm{mol}^{-1}$ ) due to plant photosynthesis (Fig. 2) (Kläring et al., 2007). Similar results were found by Dannehl et al. (2014), who detected the $\mathrm{CO}_{2}$ concentration would greatly limit to $250 \mu \mathrm{mol} \cdot \mathrm{mol}^{-1}$ when plant photosynthesis was well done in conventional greenhouses. Most carbohydrates that would construct cucumber yield were assimilated while the $\mathrm{CO}_{2}$ concentration was low in the greenhouse at that time. This was also the reason that the correlation coefficient between $\mathrm{CO}_{2}$ and yield was minus (Fig. 3). The greenhouse $\mathrm{CO}_{2}$ concentration was significantly correlated with temperature, as cucumber photosynthesis was higher at suitable temperature and consumed more $\mathrm{CO}_{2}$, which resulted in low $\mathrm{CO}_{2}$ concentration in the greenhouse.

Considering all climate factors together, we developed the best regression models for cucumber yields (Fig. 4). Our overall model equations of Yield_ave and Yield_Lincluded the climate variables of RH_ave, T_day, T_ave, and R_sum, which are all the most important factors for greenhouse cucumber production (Qian et al., 2015). The 67\% of the variation of yield could be explained by these variables, higher than any single regression model (Figs. 3 and 4). The model fit the measurements very well. The measured yields of weeks 19 to 31,2016 , and weeks 1 to 7 , 2017 , were slightly lower than simulated data. The major reason was due to cultivation mismanagement caused pest and disease damage and glass transmittance reducing (not washing on time) at weeks 19 to 31,2016 , and plant senescence at weeks 1 to 7, 2017.

For Yield_H, although the overall model only included the T_day, T_ave, and R_sum, the model $R^{2}$ values were also higher $(0.64$, $P<0.0001$ ) (Fig. 4). These statistical metrics support that the best regression models of 


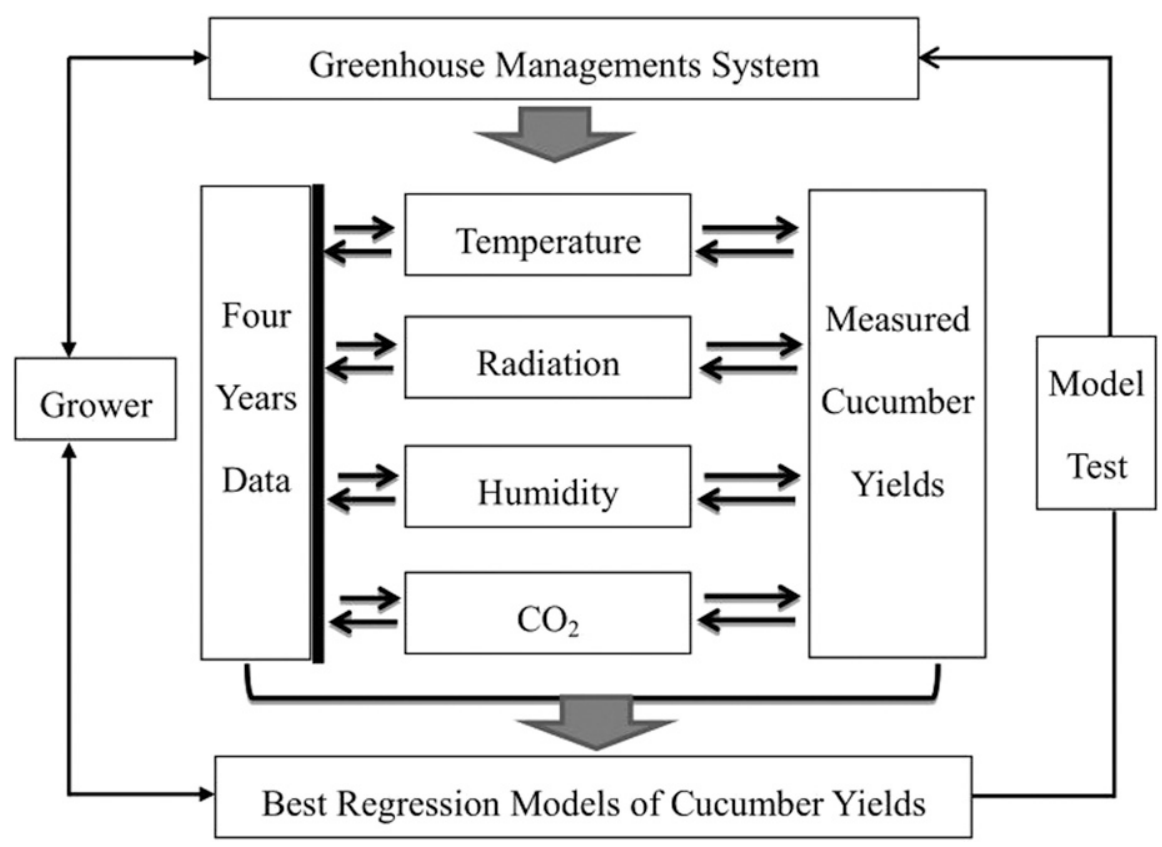

Fig. 5. Typical control hierarchy for "semi-closed" greenhouse management system and the construction process of cucumber yield models.

Yield_ave, Yield_L, and Yield_H simulated average, lowest, and highest yield well in the semi-closed greenhouse.

Our results showed that R_sum and greenhouse temperature significantly contributed to yields. Among these variables, total solar radiation was the most important factor (R_sum > T_day > T_ave > T_night) (Fig. 3; Table 1). To increase cucumber yield, we may need to increase solar radiation, and maintain optimal greenhouse temperature. Greenhouse production is carried out by taking advantage of favorable climate (light, air temperature, relative humidity, and $\mathrm{CO}_{2}$ concentration) while reducing the operational cost (Hassanien et al., 2016). To increase solar radiation in the greenhouse, more transparent but low-cost greenhouse roofs may be needed. Meanwhile, it is important to clean the greenhouse glass regularly, for example, during the time of no cucumber cultivation. Temperature should be maintained not too low in winter (night temperature $>15^{\circ} \mathrm{C}$ ) and not too high in summer (day temperature better $<35^{\circ} \mathrm{C}$ ). This could be achieved by increasing air circulation between the outside and inside of the greenhouse, shading during summer, and window opening when the temperature is too high. Although we did not find a significant relationship between yield and $\mathrm{CO}_{2}$ concentration, increasing outside $\mathrm{CO}_{2}$ supplement during the day and maintaining nighttime relative humidity $\approx 90 \%$ might increase cucumber yield. Meanwhile, the greenhouse energy management should consider the market and cost.

\section{Conclusions}

Simulating cucumber yield based on environmental and cultivation practices is quite new in semi-closed greenhouses in China. Previous greenhouse cucumber management is mainly based on experience with cultivation, climate control, and market demand. As far as we know, this is the first attempt to build cucumber yield models in semi-closed greenhouses in China, based on 4 years of ronmental factors. We found the following: 1) Total solar radiation, greenhouse air temperature, and humidity showed strong seasonal variations, and total radiation had the highest correlation coefficient with cucumber yield; and 2) the best regression models adequately simulated seasonal changes of weekly cucumber yields (i.e., mean, the highest and lowest yields). Solar radiation and temperature played important roles in determining cucumber yields. The information generated in this study could be very helpful for improving cucumber yield, cultivation, and management practices in semiclosed greenhouses (Fig. 5).

\section{Literature Cited}

Alsadon, A., I. Al-Helal, A. Ibrahim, A. AbdelGhany, S. AlZaharani, and T. Ashour. 2016. The effects of plastic greenhouse covering on cucumber (Cucumis sativus L.) growth. Ecol. Eng. 87:305-312.

Boaventura, J. and J.P. de Moura. 2003. Optimal management of greenhouse environments. In: Proceedings of EFITA 2003 Conference, Debrecen, Hungary, 5-9 July 2003; p. 559564.

Boulard, T., J.C. Roy, J.B. Pouillard, H. Fatnassi, and A. Grisey. 2017. Modelling of micrometeorology, canopy transpiration and photosynthesis in a closed greenhouse using computational fluid dynamics. Biosyst. Eng. 158:110-133.

Cockshull, K.E. 1988. The integration of plant physiology with physical changes in the greenhouse climate. Acta Hort. 229:113-123. measurements of cucumber yields and envi-
Dai, J.F., S.S. Liu, W.R. Zhang, R. Xu, W.H. Luo, S.F. Zhang, X.Y. Yin, L. Han, and W.P. Chen. 2011. Quantifying the effects of nitrogen on fruit growth and yield of cucumber crop in greenhouses. Scientia Hort. 130:551-561.

Dannehl, D., M. Josuttis, C. Ulrichs, and U. Schmidt. 2014. The potential of a confined closed greenhouse in terms of sustainable production, crop growth, yield and valuable plant compounds of tomatoes. J. Appl. Bot. Food Qual. 87:210-219.

De Gelder, A., J.A. Dieleman, G.P.A. Bot, and L.F.M. Marcelis. 2012. An overview of climate and crop yield in closed greenhouses. J. Hort. Sci. Biotechnol. 87:193-202.

Ding, X.T., Y.P. Jiang, H. Wang, H.J. Jin, H.M. Zhang, C.H. Chen, and J.Z. Yu. 2013. Effects of cytokinin on photosynthetic gas exchange, chlorophyll fluorescence parameters, antioxidative system and carbohydrate accumulation in cucumber (Cucumis sativus L.) under low light. Acta Physiol. Plant. 35:1427-1438.

Ding, X.T., Y.P. Jiang, T. Hao, H.J. Jin, H.M Zhang, L.Z. He, Q. Zhou, D.F. Huang, D.F. Hui, and J.Z. Yu. 2016. Effects of heat shock on photosynthetic properties, antioxidant enzyme activity, and downy mildew of cucumber ( $\mathrm{Cucu}$ mis sativus L.). PLoS One 11(4):E0152429.

Dorais, M., A.P. Papadopoulos, and A. Gosselin. 2001. Greenhouse tomato fruit quality. Hort. Rev. 26:239-319.

Duarte-Galvan, C., I. Torres-Pacheco, R.G. Guevara-Gonzalez, R.J. Romero-Troncoso, L.M. Contreras-Medina, M.A. Rios-Alcaraz, and J.R. Millan-Almaraz. 2012. Advantages and disadvantages of control theories applied in greenhouse climate control systems. Spanish J. Agr. Res. 10:926-938.

Fanourakis, D., S.M. Carvalho, D.P. Almeida, and E. Heuvelink. 2011. Avoiding high relative air humidity during critical stages of leaf ontogeny is decisive for stomatal functioning. Physiol. Plant. 142:274-286.

Gieling, T.H., J.B. Campen, J.A. Dieleman, N. Garcia, and H.J.J. Janssen. 2011. Monitoring of climate variables in semi-closed greenhouses. Acta Hort. 893:1073-1080.

Hassanien, R.H.E., M. Li, and W.D. Lin. 2016. Advanced applications of solar energy in agricultural greenhouses. Renew. Sustain. Energy Rev. 54:989-1001.

Kaukoranta, T., J. Näkkilä, L. Särkkä, and K. Jokinen. 2014. Effects of lighting, semi-closed greenhouse and split-root fertigation on energy use and $\mathrm{CO}_{2}$ emissions in high latitude cucumber growing. Agr. Food Sci. 23:220-235.

Kläring, H.P., C. Hauschild, A. Heißner, and B. Bar-Yosef. 2007. Model-based control of $\mathrm{CO}_{2}$ concentration in greenhouses at ambient levels increases cucumber yield. Agr. For. Meteorol. 143:208-216.

Lebeda, A. and Y. Cohen. 2011. Cucurbit downy mildew (Pseudoperonospora cubensis): Biology, ecology, epidemiology, host-pathogen interaction and control. Eur. J. Plant Pathol. 129:157-192.

Li, H., F. Wang, X.J. Chen, K. Shi, X.J. Xia, M.J. Considine, J.Q. Yu, and Y.H. Zhou. 2014. The sub/supra-optimal temperature-induced inhibition of photosynthesis and oxidative damage in cucumber leaves are alleviated by grafting onto fig leaf gourd/luffa rootstocks. Physiol. Plant. 152:571-584.

Liu, B.B., M. Li, Q.M. Li, Q.Q. Cui, W.D. Zhang, X.Z. Ai, and H.G. Bi. 2018. Combined effects of elevated $\mathrm{CO}_{2}$ concentration and drought stress on photosynthetic performance and leaf 
structure of cucumber (Cucumis sativus L.) seedlings. Photosynthetica 56:942-952.

Marcelis, L.F.M. 1992. The dynamics of growth and dry matter distribution in cucumber. Ann. Bot. 69:487-492.

Marcelis, L.F.M., A.G.M. Broekhuijsen, E. Meinen, E.M.F.M. Nijs, and M.G.M. Raaphorst. 2006. Quantification of the growth response to light quantity of greenhouse grown crops. Acta Hort. 711:97-103.

Marcelis, L.F.M., E. Heuvelink, and J. Goudriaan. 1998. Modelling biomass production and yield of horticultural crops: A review. Scientia Hort. 74:83-111.

Nederhoff, E.M. and J.G. Vegter. 1994. Photosynthesis of stands of tomato, cucumber and sweet pepper measured in greenhouses under various $\mathrm{CO}_{2}$-concentrations. Ann. Bot. 73:353-361.

Opdam, J.J.G., G.G. Schoonderbeek, E.B.M. Heller, and A. de Gelder. 2005. Closed greenhouse:
A starting point for sustainable entrepreneurship in horticulture. Acta Hort. 691: 517-524.

Qian, T., J.A. Dieleman, A. Elings, A. De Gelder, and L.F.M. Marcelis. 2015. Response of tomato crop growth and development to a vertical temperature gradient in a semi-closed greenhouse. J. Hort. Sci. Biotechnol. 90:578-584.

Qian, T., J.A. Dieleman, A. Elings, and L.F.M. Marcelis. 2012. Leaf photosynthetic and morphological responses to elevated $\mathrm{CO}_{2}$ concentration and altered fruit number in the semi-closed greenhouse. Scientia Hort. 145:1-9.

Qian, T., J.A. Dieleman, A. Elings, A. De Gelder, L.F.M. Marcelis, and O. Van Kooten. 2011. Comparison of climate and production in closed, semi-closed and open greenhouses. Acta Hort. 893:807-814.

Tian, L.G., Q.H. Meng, L.P. Wang, and J.H. Dong. 2014. A study on crop growth environment control system. Intl. J. Control Autom. 7:357374.

Vandenbussche, F., W.H. Vriezen, J. Smalle, L.J. Laarhoven, F.J. Harren, and D. Van Der Straeten. 2003. Ethylene and auxin control the Arabidopsis response to decreased light intensity. Plant Physiol. 133:517-527.

Xu, R., J. Dai, W. Luo, X. Yin, Y. Li, X. Tai, L. Han, Y. Chen, L. Lin, G. Li, C. Zou, W. Du, and M. Diao. 2010. A photothermal model of leaf area index for greenhouse crops. Agr. For. Meteorol. 150:541-552.

Zhou, X., Z.M. Ge, S. Kellomaki, K.Y. Wang, H. Peltola, and P. Martikainen. 2011. Effects of elevated $\mathrm{CO}_{2}$ and temperature on leaf characteristics, photosynthesis and carbon storage in aboveground biomass of a boreal bioenergy crop (Phalaris arundinacea L.) under varying water regimes. Glob. Change Biol. Bioenergy $3: 223-234$. 